\title{
EFFECT OF PLATELET-RICH PLASMA, FAT PAD AND DURAL MATRIX IN PREVENTING EPIDURAL FIBROSIS
}

\author{
EFEITO DO PLASMA RICO EM PLAQUETAS, ENXERTO \\ DE GORDURA E MATRIZ DE COLÁGENO NA \\ PREVENÇÃO DA FIBROSE EPIDURAL
}

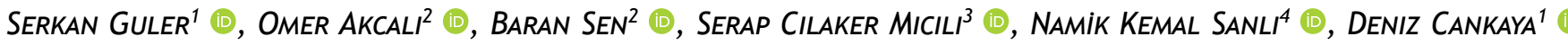 \\ 1. Aksaray University, Faculty of Medicine, Department of Ortopaedic and Traumatology, Aksaray, Turkey. \\ 2. Dokuz Eylul University, Faculty of Medicine, Department of Ortopaedic and Traumatology, Izmir, Turkey. \\ 3. Dokuz Eylul University, Faculty of Medicine, Department of Histology, Izmir, Turkey. \\ 4. Dokuz Eylul University, Faculty of Medicine, Department of Haematology and Oncology, Izmir, Turkey.
}

\section{ABSTRACT}

Objective: Epidural fibrosis is one of the main reasons for requiring repeated surgical intervention. Our objective was to compare the effect of Platelet Rich Plasma (PRP) on the development of epidural fibrosis with collagen dural matrix and free autogenous fat graft. Methods: Male rats were separated into 3 groups. Laminectomy was implemented on the rats and epidural fat pad was placed in the first group ( $n=7$ ); equal size of collagen dural matrix was applied in the second group ( $n=7$ ); a single dose of PRP was applied in the third group $(n=7)$. Results: Epidural fibrosis was more common in the group that collagen dural matrix was applied when compared the ones that PRP was applied. PRP group presented better values in preventing epidural fibrosis when compared to the fat pad group, however this difference was not statistically significant. Conclusion: PRP is a material that can be easily obtained from the very blood of patients and at an extremely low cost; the main clinical relevance of our study is that the PRP might be an efficient material for better clinical results after laminectomy surgery due to its tissue healing and epidural fibroris preventing potentials. Level of Evidence V, Animal research.

Keywords: Platelet-Rich Plasma. Laminectomy. Fibrosis. Collagen.

\section{RESUMO}

Objetivo: A fibrose epidural é uma das principais razões que motiva intervenções cirúrgicas repetidas. O objetivo deste estudo foi comparar o efeito do plasma rico em plaquetas (PRP) no desenvolvimento de fibrose epidural com matriz de colágeno e enxerto de gordura autógena. Métodos: Ratos machos foram separados em 3 grupos. A laminectomia foi aplicada nos ratos e gordura epidural foi colocada no primeiro grupo $(n=7)$; matriz de colágeno de tamanho igual foi aplicada no segundo grupo ( $n=7)$; uma dose única de PRP foi aplicada no terceiro grupo ( $n$ =7). Resultados: A fibrose epidural foi mais comum no grupo em que a matriz de colágeno foi aplicada, quando comparada aos animais do grupo PRP. O grupo PRP apresentou os melhores valores na prevenção da fibrose epidural quando comparado ao grupo enxerto de gordura, porém a diferença não foi estatisticamente significante. Conclusão: PRP é um material de fácil obtenção do sangue dos pacientes e a baixo custo; a principal relevância clínica de nosso estudo é que o PRP pode ser um material eficiente para obter melhores resultados clínicos após a laminectomia devido à sua cicatrização tecidual e potencial de prevenção de fibrose epidural. Nível de evidência V, Pesquisa com animais.

Descritores: Plasma Rico em Plaquetas. Laminectomia. Fibrose. Colágeno.

Citation: Guler S, Akcali O, Sen B, Micili SC, Sanli NK, Cankaya D. Effect of platelet-rich plasma, autogenous fat pad and collagen dural matrix in preventing epidural fibrosis in rat models after laminectomy. Acta Ortop Bras. [online]. 2020;28(1):31-5. Available from URL: http://www.scielo.br/aob.

\section{INTRODUCTION}

Low back pain is a recurrent clinical situation even after surgical treatment of disc herniation lumbar spine surgeries. ${ }^{1,2}$ In some cases, recovery is achieved by light scale medical intervention or minimally invasive methods, but in some cases postoperative back pain is not relieved, even with interventions such as complex surgeries. ${ }^{1,3-5}$ Failed back surgery syndrome is characterized by recurrent continued pain after neurosurgical intervention such as lumbar laminectomy, and has gained the attention from spinal surgeons. ${ }^{5-7}$

Epidural fibrosis is a natural outcome of laminectomy, being the formation of excessive scar tissue at the surgical site..$^{2,4,8}$ The literature has already reported that scars may cause clinically significant sequalae by creating adherences in between the tissues, or as a result of the dense fibrous tissue exerting pressure on the surrounding anatomical structures. ${ }^{1-9}$ Although there is no consensus on the

All authors declare no potential conflict of interest related to this article.

Study was conducted at the Dokuz Eylul University, Alsancak, Turkey.

Correspondence: Deniz Cankaya. Aksaray University, Faculty of Medicine, Department of Orthopaedics and Traumatology. Bahcesaray Mahallesi 68100. Aksaray, Turkey. cankayadeniz78@gmail.com 
ratio of fibrosis related problems, the possibility has been considered in many studies that, if there was no alternative bone or vertebral disk pathology, the cause of recurrent symptoms following lumbar disc surgery interventions may be fibrosis. ${ }^{2,5,7-9}$ The literature has already stated that $24 \%$ of the reasons patients required repeated surgical intervention was epidural fibrosis. ${ }^{9}$

Approaches using the minimally invasive techniques, drugs, biomaterial and non-biomaterial barriers to prevent the postoperative epidural adhesion were intensively investigated, ${ }^{3}$ and several studies are being conducted to prevent or reverse the development of epidural fibrosis. ${ }^{10}$ Among these materials, platelet-rich plasma (PRP) can be defined as a plasma fraction with platelet concentration higher than the baseline concentration in whole blood and that has antifibrotic action. ${ }^{11}$ Autologous fat grafts have been commonly used to prevent the epidural adhesion after lumbar laminectomy. ${ }^{3,12}$ Collagen dural matrix (DuraGen) is a chemical cross-linked type 1collagen foam made from bovine tendon and has been suggested to reduce fibrosis. ${ }^{13}$ However, all articles on the literature emphasize the need for further studies on the preventive nature of these materials. As previously mentioned, the effects of PRP, autologous fat graft and collagen dural matrix on the development of epidural fibrosis after laminectomy have been investigated individually. However, little attention has been given to a comparative analysis of all these factors. The objective of this study was to analyze the comparative effect of the intraoperative application of PRP, autologous fat graft and collagen dural matrix on the prevention of epidural fibrosis after laminectomy in an experimental model with rats.

\section{METHODS}

Twenty-eight rats were randomly divided into four groups of 7 rats. One rat was used for a pilot study for laminectomy and PRP preparation, not included in this study. All specimens were Wistar rats (250-300 gram) and were housed individually at $22^{\circ} \mathrm{C}$ with a twelve-hour light/twelve-hour dark cycle in Animal Research Facilities. The research procedures were in full compliance with Veterinary Medicine Deontology Regulation 6.7.26, Helsinki Declaration of Animal Rights, and approved by the University Ethics Committee of Animal Research (approval number 61/2012). Surgical interventions were performed by a single surgeon. Induction of anesthesia was performed by intraperitoneal ketamine hydrochloride $35 \mathrm{mg} / \mathrm{kg}$ and xylazine hydrochloride $5 \mathrm{mg} / \mathrm{kg}$. Following anesthesia, the subjects were immobilized in prone position. The lumbar region was shaved, and the surgical site was prepared. Local antisepsis was achieved using povidone-iodine. The lumbar area was determined by taking interscapular distance as reference, and a $4 \mathrm{~cm}$ midline skin incision was applied at L1-L5 level. Subcutaneous tissues and paraspinal muscles are divided and a small self-retaining retractor was used for exposure. The areas between the sacrum and L3 spinous process were exposed. L3 and L4 total laminectomy and ligamentum flavum excision was performed by a small Kerrison rongeur. All layers were sutured in anatomic architecture.

The posterior surface of the dura in the laminectomy site were covered with fat pad in Group $1(n=7)$. In Group $2(n=7)$, collagen dural matrix (DuraGenPlus ${ }^{T M}$ ) of equal size $(4 \times 2.5 \mathrm{~mm})$ were used for coverage. Single dose (1.5cc) PRP were applied over dura mater in Group $3(n=7)$. Seven additional rats (Donation Group) were used to obtain cardiac blood for PRP preparation. One rat was used for pilot study for laminectomy and PRP preparation and was not included into the study. After applying the materials, all layers were sutured in anatomic architecture. Preoperative and postoperative (24th and 48th hours) neurologic status of the subjects was determined by Basso, Beattie and Bresnahan (BBB) scoring system. ${ }^{14}$
PRP was prepared by obtaining $10 \mathrm{cc}$ blood from a rat in the donation group and put into tubes with citrate phosphonate dextrose (CPD). Additional $0.5 \mathrm{cc}$ blood put into pediatric tubes with EDTA and sent to the autoanalyzer for cell count;10 cc blood with citrate were transported to the hematology laboratory in the cold chain for the preparation of PRP. The sample was centrifuged for 10 minutes at $1500 \mathrm{rpm}$ and $10{ }^{\circ} \mathrm{C}$. Supernatant plasma and buffy-coat were taken and separated from the blood cells. Following, it was centrifuged for 10 minutes at $2000 \mathrm{rpm}$. The supernatant thrombocyte-poor part was separated and kept to be used for dilution during measurement. The sediment was centrifuged again at $2500 \mathrm{rpm}$ and $1.5 \mathrm{cc}$ PRP was obtained from the bottom $1 / 3$ part. To achieve a gelatinous texture, $0.30 \mathrm{cc}$ of $10 \% \mathrm{CaCl} 2$ was added using a micropipette. All procedures in the laboratory were performed under sterile conditions. The samples were transported to the animal laboratory in the cold chain and used in epidural PRP application.

The rats in all three groups were sacrificed at the end of 4th week. Their spinal column was excised as an en-block that contained upper and lower intact segments of laminectomy level. Histological examinations were done at the Histology Department by using a light microscope operated by a senior histologist who was blinded to the groups. Tissue samples were kept in $10 \%$ formaldehyde for 24-48 hours for fixation, and then placed in a EDTA solution for 8 weeks for bone tissue softening. Two sets of paraffine were applied in a $60^{\circ} \mathrm{C}$ incubator, each for 1 hour; immersion was thus achieved, and tissues were embedded inside paraffine blocks after the acetone solution treatment process. Cross sections sized $5 \mu \mathrm{m}$ were taken from paraffine blocks by microtome. They were then treated in 4 changes of acetone solutions, each for 20 minutes, kept in 2 changes of acetone solutions each for 30 minutes. Following, $5 \mu \mathrm{m}$ paraffine cross sections were left in the $60^{\circ} \mathrm{C}$ incubator overnight for the deparaffinization process, being exposed to 3 changes of xylol, each for 20 minutes. After 10 minutes of staining with hematoxylin, they were washed under running water for 10 minutes to remove excessive stain from the tissue, and then stained for 2 minutes with eosin stain. Following, the cross sections were treated with alcohol series of $80 \%$ and $95 \%$, respectively and then dried in air. They were treated with two changes for transparentization for 30 minutes each and covered with Entellan.

The method of $\mathrm{He}$ et al. was used to evaluate the epidural fibrosis. ${ }^{15}$ This classification presents additional definitions for the degree of severity, ranges from normal to a severe degree of epidural fibrosis, and is described as follows: grade 0 (normal, no epidural fibrosis), grade 1 (mild degree, thin fibrous band(s) over dura), grade 2 (moderate degree, continuous adherence observed but less than two-thirds of laminectomy defect), and grade 3 (severe fibrosis, large scar tissue adherence, more than two-thirds of laminectomy area, and/or extending to nerve roots). ${ }^{15,16}$ Epidural fibrosis classification is shown to have almost perfect agreement among the assessors with its high interrater reliability. ${ }^{16}$

The results were evaluated with SPSS for Windows. When the structure of the study groups and study design were considered, for statistical comparison, the Kruskal Wallis variance analysis test was used to compare three groups between each other, whereas Mann-Whitney's U test with Bonferroni's correction was used for bilateral comparison within groups. Statistical significance was considered when $\mathrm{P}<0.05$.

\section{RESULTS}

All subjects survived throughout the study. No allergic, infectious and foreign body reaction findings were observed. Axial cross sections of the spine segments at laminectomy level 
were histologically examined. Grade 1 fibrosis was noticed in five samples (71\%) in group 1 (fat pad group), and grade 2 fibrosis was determined in the remaining two samples; moreover, fibrotic extensions were also determined as less than 2/3 of the cross section. Grade 3 findings were not observed. Intensive revascularization areas were observed on medulla spinalis and duramater with 10x magnification examination of the samples in this group (Figure 1). At higher magnification (20x), grade 1 fibrosis was also observed as thin fibrotic bands besides the revascularization areas (Figure 2 ).

In Group 2 (collagen dural matrix), grade $1(\mathrm{n}=2)$ and grade 2 $(n=2)$ fibrosis were equal in four of seven subjects in total. In the remaining three samples, fibrotic scar tissues were observed with more than $2 / 3$ of the cross-section area and extending up to the nerve stems that can be visualized. These three cases were classified as grade 3 (43\%). Dense fibrous tissue formation and plenty of fibroblasts are the main different findings when compared to the others. In some samples, we observed that fibrous tissue was dense and the development of scar tissue became apparent (Figure 3). In other examples, histological findings corresponding to scar tissue development were not determined. However, collagen dural matrix residues were also

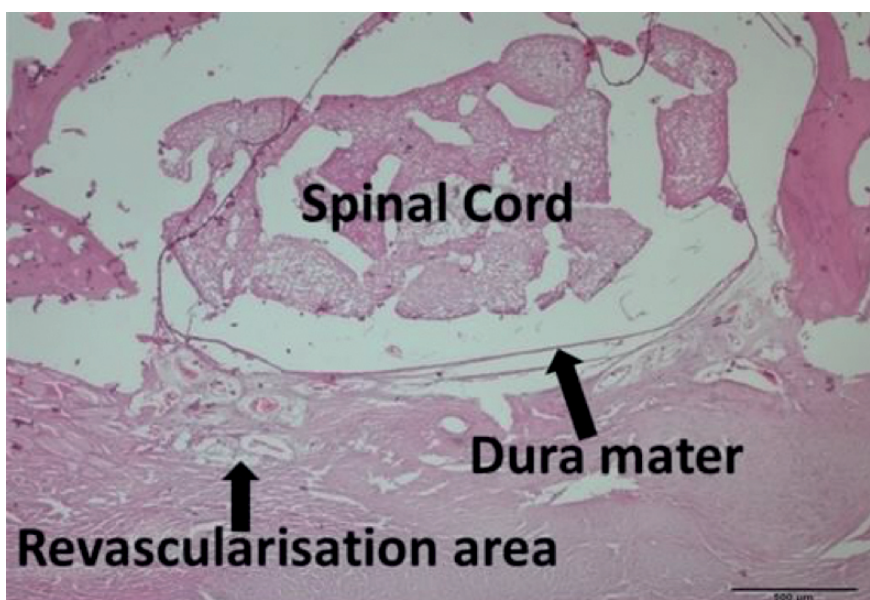

Figure 1. In the free fat pad applied sample (Group 1), intensive revascularization areas are seen right above dura mater (10x magnification).

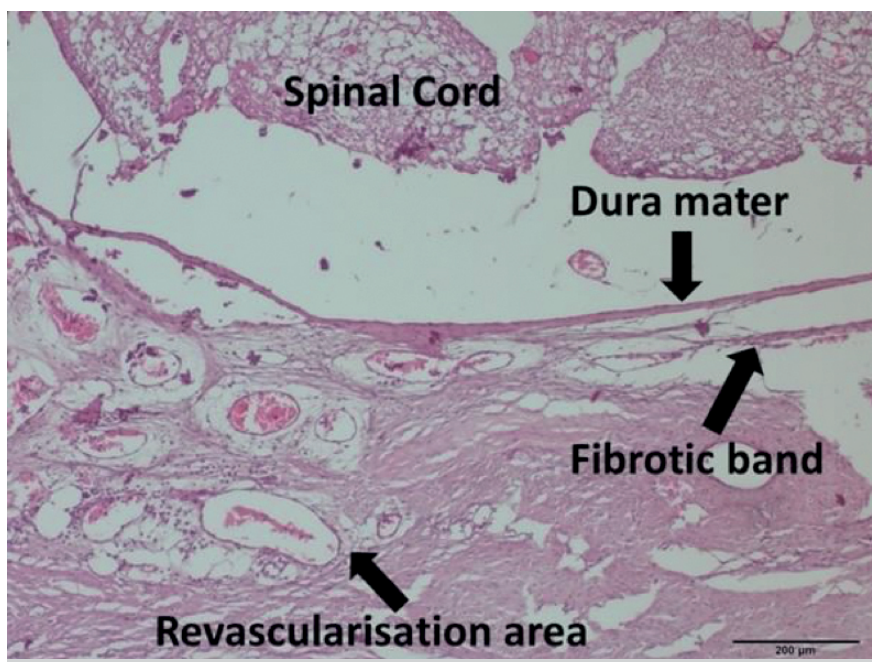

Figure 2. In the histological cross-section of a free fat pad applied sample (Group 1), fibrotic band can be distinguished between dura mater and the revascularization areas and it can be evaluated as grade 1 (20x magnification). observed in the histological cross-section through laminectomy area at higher level magnification (20x). Dense fibrous tissue was covered more than $2 / 3$ of epidural space after collagen dural matrix application (Figure 4).

In Group 3 (PRP group), no fibroblastic activity was determined in one sample and was accepted as grade 0 (14\%). One subject showed grade 2 fibrosis. Grade 1 fibrosis (71\%) was observed in the rest of the subjects $(n=5)$. Epidural fibroblasts were rare. In the epidural tissue, histologically fibrous tissue was scarce and cellular properties were observed that are very similar to those where surgery was not applied. Recovery findings in the epidural tissue were observed close to those of the classical descriptions. At higher magnification (20x), the sample taken from the PRP group showed revascularization areas that were observed in the free autogenous fat pad placed group that were not detected. Collagen fibers in the tissue were dense; however, the data cannot be assessed quantitatively since grading via collagen staining was not implemented. Figure 5 shows a sample in which the fibrosis level was determined as grade 0 . Statistical comparison of three groups is shown in Table 1. Paired comparison of groups and $p$ values are shown in Table 2 .

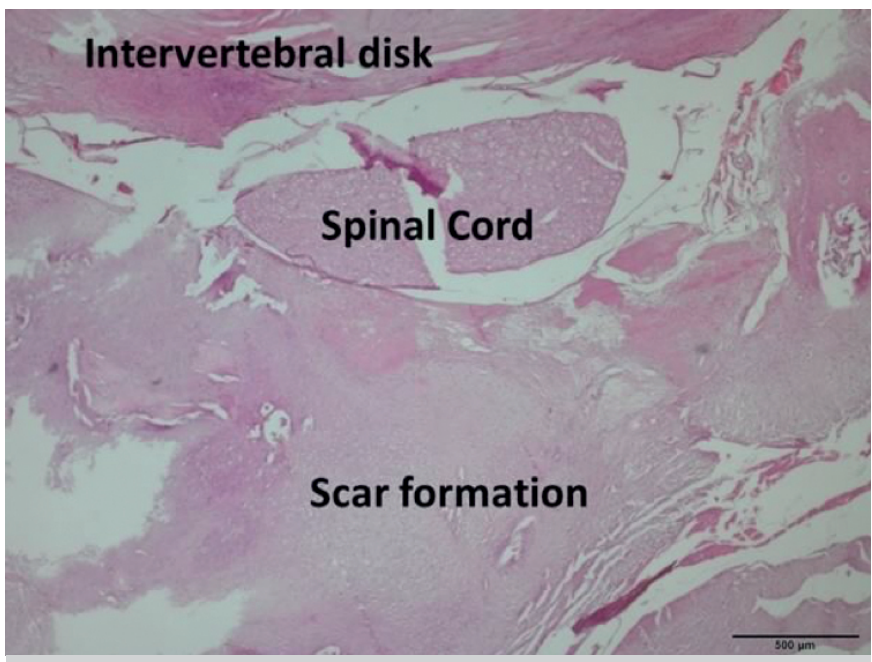

Figure 3. Scar tissue development in the sample that collagen dural matrix was applied (Group 2) (10x magnification).

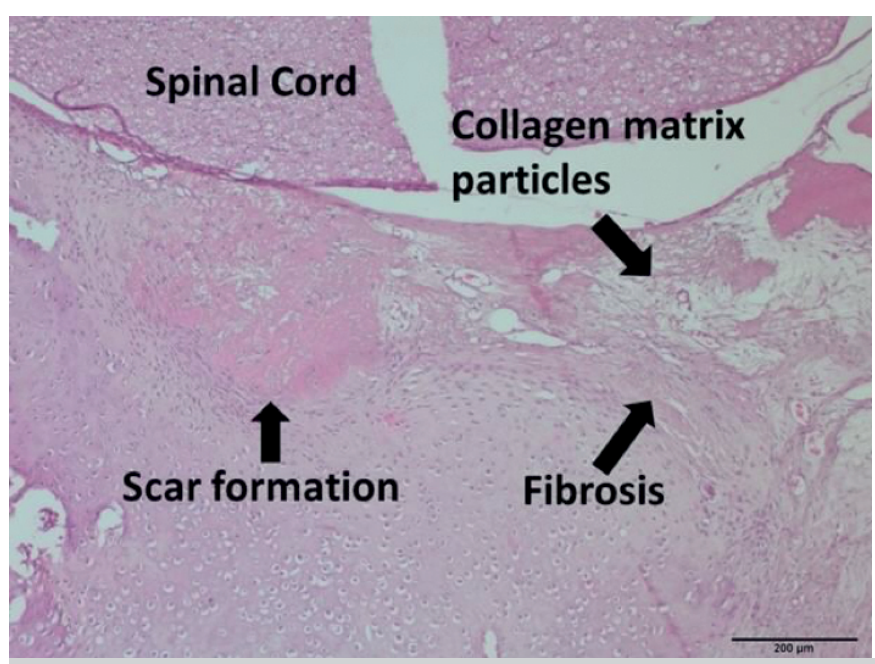

Figure 4. In higher magnification images of the sample that collagen dural matrix was applied (Group 2), scar and fibrosis tissue (20x magnification). 


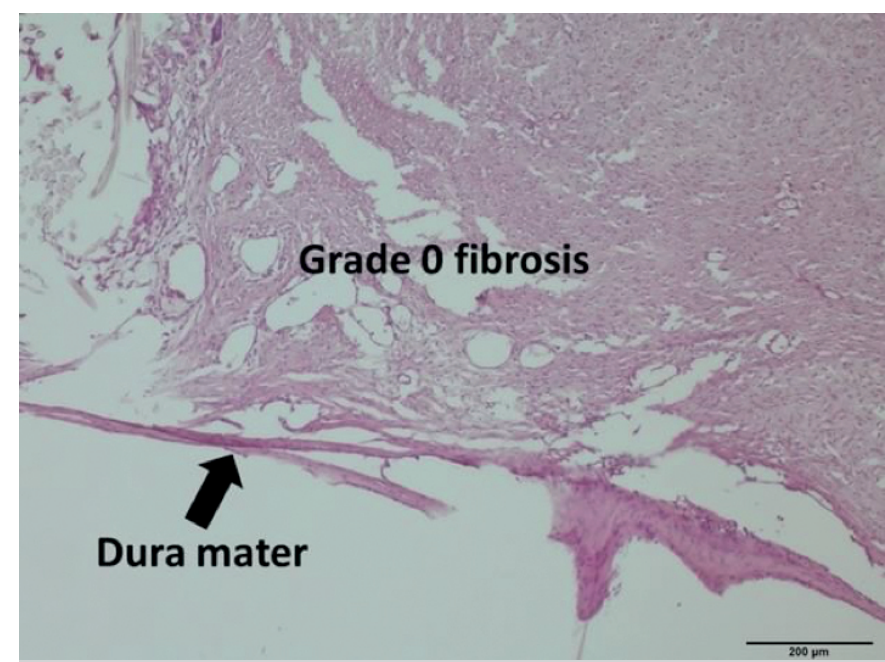

Figure 5. A sample from the PRP applied group where fibrosis grade 0 was determined (20x magnification).

Table 1. The results of non-parametric evaluation of histological examinations. Comparison of histological fibrosis grading data of three experimental groups with each other was implemented by Kruskal Wallis's test. The difference of the distributions of histological results of three experimental groups were statistically significant $(p<0.05)$.

\begin{tabular}{c|c|c|c}
\hline Sample (n) & Fat Pad & Collagen matrix & PRP \\
\hline 1 & 1 & 2 & 1 \\
\hline 2 & 1 & 3 & 2 \\
\hline 3 & 1 & 3 & 1 \\
\hline 4 & 1 & 1 & 1 \\
\hline 5 & 2 & 1 & 1 \\
\hline 6 & 1 & 3 & 0 \\
\hline 7 & 2 & 2 & 1 \\
\hline
\end{tabular}

Table 2. Paired comparisons of the groups by Mann-Whitney's $U$ test.

\begin{tabular}{c|c}
\hline Groups & p values \\
\hline Fat pad - Collagen Matrix & 0.097 \\
\hline Collagen Matrix - PRP & $0.038^{\star}$ \\
\hline Fat pad - PRP & 0.456 \\
\hline
\end{tabular}

*Statistically significant difference was found between collagen dural matrix group and PRP group $(p<0.05)$

\section{DISCUSSION}

Despite the application of all treatment modalities, patients who undergo posterior spinal surgery - including laminectomy - may develop epidural fibrosis. Clinically, late leg pain may result from epidural and perineural fibrosis. Epidural fibrosis may display clinical view by adhering to the dura mater, nerve roots, erector spinae muscles, intervertebral disk and vertebrae. Several biological and non-biological materials have been tested to prevent epidural fibrosis - which is considered one of the most prominent factors of lumbar pain that persists after lumbar spinal surgery., ${ }^{3,12,17,18}$ Free autogenous fat grafts, collagen matrix (DuraGen ${ }^{\mathrm{TM}}$ ), hyaluronic acid, licofelone, Seprafilm ${ }^{\mathrm{TM}}$, Adcon- $\mathrm{L}^{\mathrm{T}}$, PRP and Rapamycin, etc. are the prominent experimental materials. 2,4-7,9,12,13,15,16,18,19 Some of these materials have been used clinically. Although most studies are animal experiments, as of today, satisfactory clinical studies confirming that these materials can help attenuate fibrosis in clinical applications have not been achieved yet. DuraGenPlus ${ }^{\mathrm{TM}}$ (Integra LifeSciences Corporation 311 Enterprise Drive Plainsboro, NJ 08536, chemical cross-linked type 1collagen foam made from bovine tendon) is a collagen matrix with spongy texture, generally used as graft for covering dural defects. ${ }^{13,20}$ This component is resorbed in 6-8 weeks and it is not encapsulated, thus undergoing a purification process to decrease foreign body reaction, and encapsulation with fibrosis and immune reactions. Some studies have been published proposing that it can decrease fibrosis in spinal surgery ${ }^{13,20,21}$

In experimental modelling, the application of fat grafts was frequently preferred among these materials to prevent fibrosis. Bryant, Bremer \& Nyugen studied 44 free autogenous fat graft applications. ${ }^{7}$ They proposed that the application of autogenous fat grafts increased the revascularization during the healing stage, so fibrotic tissue could thus be prevented. Similar to our study, the formation of revascularization was distinguishable in the fat graft areas and decrease in fibrotic tissue formation was histologically observed. But no sufficient data was obtained to allow us to comment on the contribution of fat application to increase vascularization, underlying reasons, and the vascularization mechanism effect on the decrease of fibrotic tissue. However, another clinical study reported the results of 99 patients operated due to lumbar disc herniations and concluded that the fat grafts were clinically ineffective in preventing epidural fibrosis. ${ }^{12}$ In our study, when comparing the fibrosis grade of the autogenous fat graft group to that of the PRP group, we observe that the PRP group has better values in preventing epidural fibrosis but that this difference did not create statistical difference. PRP is a popular material in the field of tissue healing after trauma or surgery, and became the hot topic of many studies nowadays. Studies about PRP use in spinal surgery are limited, but we found no studies comparing the fibrotic effects of PRP, fat pad, and frequently used biologic material such as collagen dural matrix. Gigante et al. published the results of an animal study on the effects of PRP on rat muscle tissues. ${ }^{22}$ They did not observe metaplasia, calcification or heterotopic ossification during the healing process following PRP application on paravertebral muscle lesions. Similarly, no abnormal cell formations in the PRP group were observed in our study. Any fibrosis formation beyond grade 2 was not observed in these samples as well; thus, cellular reactions look similar in both studies. Intradiscal PRP applications have been studied to evaluate the disk changes in animals. Obata et al. reported a positive effect in disk regeneration with PRP application following disk degeneration in a rabbit model and observed an increase in collagen matrix and type 2 collagen rate in nucleus pulposus cells. ${ }^{23}$

As limitations of our study we can cite its experimental character, which limits the direct application of the results to clinical practice, like in any other experimental study. Due to the ethical regulations in providing experimental animals, we were unable to obtain the minimum number of experimental animals according to the nonparametric statistical tests. Selecting small animals such as rats can also be a disadvantage, given that working with larger animals would be easier when considering the surgical technique and histological slice preparations.

\section{CONCLUSION}

Our study investigated the effects of two frequently used materials in spinal surgery. There is no consensus in the literature due to the studies reporting positive and negative results of epidural free fat application and collagen matrix applications. Our study is the first study to compare the effects of free fat pad, collagen dural matrix, and PRP on epidural fibrosis. When the results of our study are interpreted, PRP was determined to not be superior to the fat pad, but better than collagen matrix group in preventing epidural fibrosis after laminectomy. PRP is a material that can be easily obtained from the patient's own blood and at an extremely low cost. The main clinical relevance of our study is that PRP might be an efficient material for better clinical results after laminectomy surgery with its tissue healing and epidural fibrosis preventing potentials. However, as data on this issue are limited, further studies with different amounts and application methods are needed to reach generally accepted conclusions about the routine use of PRP in lumbar discs surgery. 
AUTHORS' CONTRIBUTIONS: Each author contributed individually and significantly to the development of this study. SG: animal lab surgeries. OA*: study design. BS: data analysis and interpretation. SCM: histopathologic examination. NKS: PRP preparation and language edit. DC: literature research, writing of the article, and corresponding author.

\section{REFERENCES}

1. Atlas SJ, Deyo RA. Evaluating and Managing Acute Low Back Pain in the Primary Care Setting. J Gen Intern Med. 2011;16(2):120-31.

2. Kasimcan MO, Bakar B, Aktaş S, Alhan A, Yilmaz M. Effectiveness of the biophysical barriers on the peridural fibrosis of a postlaminectomy rat model: an experimental research. Injury. 2011;42(8):778-81.

3. Wang H, Sun W, Fu D, Shen Y, Chen YY, Wang LL. Update on biomaterials for prevention of epidural adhesion after lumbar laminectomy. J Orthop Translat. 2018;13:41-9.

4. Wu CY, Huang YH, Lee JS, Tai TW, Wu PT, Jou IM. Efficacy of topical cross-linked hyaluronic acid hydrogel in preventing post laminectomy/laminotomy fibrosis in a rat model. J Orthop Res. 2016;34(2):299-306.

5. Chen F, Zuo Z, Wang K, Zhang C, Gong H, Ye F, et al. Study on salvianolic acid $B$ in the reduction of epidural fibrosis in laminectomy rats. BMC Musculoskelet Disord. 2014;15:337.

6. Zhang K, Zhao J, Su W, Lu R, Lv P. Immunomodulatory effectiveness of licofelone in preventing epidural fibrosis in post-laminectomy rat. Eur $\mathrm{J}$ Orthop Surg Traumatol. 2015;25 Suppl 1:S63-8.

7. Wang Z, Wang Y, Xie P, Liu W, Zhang S. Calcium channel blockers in reduction of epidural fibrosis and dural adhesions in laminectomy rats. Eur J Orthop Surg Traumatol. 2014;24 Suppl 1:S293-8.

8. Lubina ZI, Baranovic S, Karlak I, Novacic K, Potocki-Karacic T, Lovrić D. The grading model for the assessment of the total amount of epidural fibrosis in postoperative lumbar spine. Eur Spine J. 2013;22(4):892-7.

9. Ross JS, Robertson JT, Frederickson RC, Petrie JL, Obuchowski N, Modic MT, et al. Association between peridural scar and recurrent radicular pain after lumbar discectomy: magnetic resonance evaluation. ADCON-L European Study Group. Neurosurgery. 1996;38(4):855-61.

10. Yu CH, Lee JH, Baek HR, Nam H. The effectiveness of poloxamer 407-based new anti-adhesive material in a laminectomy model in rats. Eur Spine $\mathrm{J}$. 2012;21(5):971-9.

11. Chellini F, Tani A, Vallone L, Nosi D, Pavan P, Bambi F, et al. Platelet-rich plasma prevents in vitro transforming growth factor-1-Induced fibroblast to myofibroblast transition: Involvement of Vascular Endothelial Growth Factor (VEGF)-A/VEGF receptor-1-mediated signaling. Cells. 2018;7(9):142.
12. Görgülü A, Simşek O, Cobanoğlu S, Imer M, Parsak T. The effect of epidural free fat graft on the outcome of lumbar disc surgery. Neurosurg Rev. 2004;27(3):181-4.

13. Tatsui CE, Martinez G, Li X, Pattany P, Levi AD. Evaluation of DuraGen in preventing peridural fibrosis in rabbits. J Neurosurg Spine. 2006;4(1);51-9.

14. Basso DM, Beattie MS, Bresnahan JC. Graded histological and locomotor outcomes after spinal cord contusion using the NYU weight-drop device versus transection. Exp Neurol. 1996;139(2):244-56.

15. He Y, Revel M, Loty B. A quantitative model of post-laminectomy scar formation: Effects of a nonsteroidal anti-inflammatory drug. Spine (Phila Pa 1976). 1995;20(5):557-63.

16. Sae-Jung S, Jirarattanaphochai K, Sumananont C, Wittayapairoj K, Sukhonthamarn K. Interrater Reliability of the Postoperative Epidural Fibrosis Classification: A histopathologic study in the rat model. Asian Spine J. 2015;9(4):587-94.

17. Braverman DL, Slipman CW, Lenrow DA. Using gabapentin to treat failed back surgery syndrome caused by epidural fibrosis: A report of 2 cases. Arch Phys Med Rehabil. 2001;82(5): 691-3.

18. Bryant MS, Bremer AM, Nyugen TQ. Autogeneic fat transplants in the epidural space in routine lumbar spine surgery. Neurosurgery. 1983;13(4):367-70.

19. Sun Y, Zhao S, Li X, Yan L, Wang J, Wang D, et al. Local application of rapamycin reduces epidural fibrosis after laminectomy via inhibiting fibroblast proliferation and prompting apoptosis. J Orthop Surg Res. 2016;11(1):58.

20. Neulen A, Gutenberg A, Takács I, Wéber G, Wegmann J, Schulz-Schaeffer W, et al. Evaluation of efficacy and biocompatibility of a novel semisynthetic collagen matrix as a dural onlay graft in a large animal model. Acta Neurochir (Wien). 2011;153(11):2241-50.

21. Zerris VA, James KS, Roberts JB, Bell E, Heilman CB. Repair of the dura mater with processed collagen devices. J Biomed Mater Res B Appl Biomater. 2007;83(2):580-8.

22. Gigante A, Del Torto M, Manzotti S, Cianforlini M, Busilacchi A, Davidson PA, et al. Platelet rich fibrin matrix effects on skeletal muscle lesions: an experimenta study. J Biol Regul Homeost Agents. 2012;26(3): 475-84.

23. Obata S, Akeda K, Imanishi T, Masuda K, Bae W, Morimoto R, et al. Effect of autologous platelet-rich plasma-releasate on intervertebral disc degeneration in the rabbit anular puncture model: a preclinical study. Arthritis Res Ther. 2012;14(6):R241. 